\title{
LA SUSTITUCIÓN DEL RETABLO MAYOR DEL MONASTERIO DE SAN LEANDRO DE SEVILLA Y SU PROMOTORA DOÑA TERESA DE ANGUIANO Y CÁRDENAS
}

\author{
THE REPLACEMENT OF THE MAIN ALTARPIECE \\ OF THE MONASTERY OF SAN LEANDRO OF SEVILLE \\ AND ITS PROMOTER MRS. TERESA DE ANGUIANO \\ Y CÁRDENAS
}

\author{
Salvador Guijo Pérez \\ Collège de Bouèni, Mayotte. Francia \\ ORCID: 0000-0002-3768-8430 \\ salvadorguijo@hotmail.com
}

\begin{abstract}
El artículo versa sobre la sustitución del retablo mayor del siglo XVI del Real Monasterio de San Leandro de Sevilla tras la entrada en el mismo de la religiosa doña Teresa de Anguiano y Cárdenas a mediados del siglo XVIII. Para la realización del mismo es preciso estudiar el retablo sustituido, así como la evolución del mismo. Todo ello se realiza principalmente a partir de la documentación inédita del monasterio. Tras dicho estudio podemos analizar el contexto en el que se generaban las obras de arte, así como las condiciones y obligaciones de los contratantes.

Palabras claves: monasterio de San Leandro de Sevilla; retablo; orden de San Agustín; Pedro Duque Cornejo; Jerónimo Hernández.
\end{abstract}

The paper deals with the replacement of the $16^{\text {th }}$ century altarpiece of the Royal Monastery of San Leandro in Seville, after the entrance of the religious Teresa de Anguiano y Cárdenas, in the mid$18^{\text {th }}$ century. For the realization of the same it is necessary to study the substituted altarpiece, as well as the evolution of it. All this is done mainly from the original documentation of the Monastery. After this study we can analyze the context in which the works of art were generated, as well as the conditions and obligations of the contractors.

Keywords: Monastery of San Leandro of Seville; altarpiece; Order of Saint Augustine; Pedro Duque Cornejo; Jerónimo Hernández. 


\section{INTRODUCCIÓN: EL RETABLO MAYOR DE FINALES DEL SIGLO XVI}

El esplendor económico del siglo XVI y su continuidad en el siglo XVII trajo consigo prosperidad a la ciudad de Sevilla así como a sus habitantes. Fruto de la misma, las familias se enriquecieron y, por consiguiente, los conventos, monasterios e instituciones religiosas, integrantes también de la sociedad sevillana, se vieron igualmente beneficiados. La religiosidad impregnaba la vida de la ciudad, los testamentos de la época se introducían habitualmente por una manifestación de fe, para acto seguido ordenar todo lo relativo al enterramiento mediante la institución de una capellanía ${ }^{1}$ o las llamadas donaciones pro remedio animae ${ }^{2}$. Así, el profundo sentimiento religioso de los fieles y el notable temor ante la muerte constituyeron el motor impulsor de abundantes donaciones a favor de las instituciones conventuales ${ }^{3}$. Del mismo modo, otra vía de adquisición de patrimonio

1 VON WOBESER, Gisel: "La función social y económica de las capellanías de misas en la Nueva España del siglo XVIII”, Estudios de historia novohispana, 16, 1996, pp. 119-138.

${ }^{2}$ Fue en el siglo VIII cuando se las llamó específicamente donaciones pro remedio animae y así se recogió tanto en documentación del sur de Alemania como en el formulario de Marculf (Formulae Marculfi). MAGNANI, Eliana: "Du don aux églises au don pour le salut de l'âme en Occident (IV $\mathrm{I}^{\mathrm{X}} \mathrm{XI} \mathrm{I}^{\mathrm{e}}$ siècle): le paradigme eucharistique", Bulletin du centre d'études médiévales d'Auxerre, BUCEMA, 2, 2008: urn:doi:10.4000/cem.9932 (versión digital); BÉRIOU, Nicole; CASAU, Béatrice y RIGAUX, Dominique (dir.): Pratiques de l'eucharistie dans les Églises d'Orient et d'Occident (Antiquité et Moyen Âge), vol. II: Les réceptions. París, 2009, pp. 1021-1042; y GODDING JOBERT, Philippe: "La Notion de donation. Convergences 630-750", Revue Belge de Philologie et d'Histoire 60 (2), 490-491, 1982, pp. 205-225. Citado por GUIJO PÉREZ, Salvador: "Relación y formación del patrimonio urbano del monasterio de San Leandro de Sevilla. Siglos XIII-XVI", Estudios sobre Patrimonio, Cultura y Ciencias Medievales, 19, 2017, p. 624.

3 “À partir de l'idée que l'Église est l'intendant des biens des pauvres, s'esquisse l'idée que l'Église est le dépositaire sur terre des biens que les bons retrouveront au ciel. Isidore de Séville (†636) explique ainsi que c'est l'église qui tient en gage à présent les biens que les bons retrouveront et dont ils jouiront dans l'avenir, car ce qui compte c'est l'usage qu'on fait des biens terrestres que Dieu a distribués indifféremment aux bons et aux mauvais". Isidoro de Sevilla: De ecclesiasticis officiis. Turnhout, 1989, p. 101. "Bona quoque temporalia bonis malisque communia a deo creari, eiusque dispensatione singulis quibusque uel tribui uel negari; quorum bonorum in unoquoque fidelium non habitus sed usus aut inprobandus est aut probandus. Certa uero aeternoaque bona solos posse bonos in futuro consequi ; quorum pignore ecclesiam nunc informatam credimus detineri, hic habentem primitias spiritus in futuro perfectionem, hic sustentari in spe, postea pasci in re, hic uidere per speculum in enigmate, in futuro autem facie ad faciem cum ad speciem fuerit perducta per fidem. Quod donec perficiatur in nobis ut summi dei bonis fruamur aeternis, fruendum in deo nouerimus et proximis". MAGNANI, Eliana: "Du don aux églises...", op. cit., p. 12. Citado por GUIJO PÉREZ, Salvador: "Relación y formación del patrimonio...”, op. cit., p. 625. 
y segundo grupo mayoritario en la documentación conservada en el archivo monacal son las adquisiciones de patrimonio mediante las dotes de las religiosas entrantes. En estos documentos de ingreso en religión, el acuerdo se produce entre los padres, o la misma interesada si es mayor de edad, y la priora y las monjas del convento en el que quiere ser admitida, con el consiguiente permiso del ordinario eclesiástico, que se traduce en la escritura en forma de licencia ${ }^{4}$. Debido a estos tipos de adquisición, sobre todo, el convento de San Leandro incrementó sus ingresos, donaciones y rentas, y gracias a ellos reformó la mayoría de sus dependencias medievales, casi en su totalidad, durante los últimos años del siglo XVI y la primera mitad del siglo XVII ${ }^{5}$. Sin embargo, el siglo XVIII fue un periodo de estancamiento, de decadencia y de revisión, incrementándose esta situación aún más en su segunda mitad. Este siglo representó una centuria decadente para las órdenes religiosas, sobre todo por la disminución del impulso que había promovido la reforma de aquellas, y la falta de ingresos y recursos económicos, debido, entre otros motivos, a la depreciación de los censos ${ }^{6}$. A nivel político se iniciaron los métodos de limitación y control del clero regular, iniciándose de una manera más visible con la expulsión de los jesuitas en $1767^{7}$. Las ideas ilustradas comenzaban su calado y fueron antesala de las posteriores desamortizaciones.

A pesar de ello y en este clima tan decadente, el monasterio recibió la entrada de una adinerada religiosa, que no solo aportó la dote necesaria para su entrada y toma de nuevo estado, pues era viuda, sino que restauró el patrimonio del monasterio con diferentes donaciones. Entre ellas, la religiosa promovió la sustitución del retablo mayor dedicado a San Leandro. El objetivo de la misma, como veremos posteriormente, fue el de perpetuar su memoria, algo que no puede resultarnos extraño ya que, como también se recoge para las capellanías, las donaciones constituyeron un elemento de status que daba reconocimiento a los donantes y a sus descendientes ${ }^{8}$.

${ }^{4}$ MARCHANT RIVERA, Alicia: Las religiosas del Císter malagueño. Catálogo de las cartas de profesión de la abadía de Santa Ana. Málaga, 2010.

${ }^{5}$ GUIJO PÉREZ, Salvador: "Sobre la contratación de retablos en la nueva iglesia del monasterio de San Leandro de Sevilla. Finales del siglo XVI y primera mitad del siglo XVII", Archivo Hispalense, 101, 306-308, 2018, pp. 91-117.

${ }^{6}$ DÍAZ LÓPEZ, Julián Pablo: "Los censos: un sistema de rentas seguras para la Iglesia del territorio almeriense en el siglo XVIII: La encuesta de 1790", Chronica nova: Revista de historia moderna de la Universidad de Granada, 24, 1997, p. 56.

7 Confróntese GIMÉNEZ LÓPEZ, Enrique: "La expulsión de los jesuitas como problema de Estado", Anales de la Real Sociedad Económica de Amigos del País, 1997-1998, pp. 249-264.

${ }^{8}$ VON WOBESER, Gisela: "La función social...", op. cit., p. 135. Dentro de una sociedad jerarquizada la posición que en ella ocupaban los individuos era un factor muy importante. En dicha época esa jerarquización social buscaba la obtención de un reconocimiento en determinados ambientes, viéndose como tales la propiedad de una capilla 
Para realizar un adecuado estudio sobre la contratación del nuevo retablo mayor suscrita por doña Teresa de Anguiano y Cárdenas en 1747, es necesario situar este en un contexto patrimonial y descriptivo de la iglesia del monasterio previo a la instalación del mismo. Para ello hemos de remitirnos a un estudio anterior nuestro, donde se describe el levantamiento de la nueva iglesia, así como la construcción de cuatro de sus retablos durante los últimos años del siglo XVI y el siglo XVII ${ }^{9}$. La construcción de la nueva iglesia del cenobio, en 1582, por Juan de Oviedo, entre otros, llevó aparejado el revestimiento de sus muros, en capillas y altares, con retablos de gran valor artístico ${ }^{10}$. El padre Llordén afirma que la traza del retablo mayor se atribuyó a Juan Bautista Vázquez y que esta fue revisada por el maestro mayor de la catedral Pedro Díaz de Palacios ${ }^{11}$. La documentación con la que contamos atribuye a los escultores Diego de Velasco y Jerónimo Hernández la ejecución de la obra, quienes, el 12 de marzo de 1582, contrataron la misma, mitad por mitad, siguiendo un memorial de condiciones ${ }^{12}$. Finalmente, el trabajo de los pintores se dio por concluido en la primera mitad del año $1594^{13}$, pasados doce años desde su contratación, lo que demuestra la envergadura que debió de tener la obra. No obstante, a pesar de su calidad, este retablo fue sustituido en 1747 por el actual de estilo barroco.

\section{EL NUEVO RETABLO MAYOR Y SU PROMOTORA}

A mediados del siglo XVIII, se realizó el retablo actual en sustitución del que había sido ejecutado, entre otros autores, por Jerónimo Hernández. Debemos consignar que las religiosas apenas se dieron cuenta de lo que se proyectaba y sintieron vivamente que se removiese el antiguo. En una declaración conjunta realizada a posteriori, en 1786, por la que entonces era abadesa del monasterio y su propia hermana, se añadió a los documentos alusivos a la sustitución del retablo

familiar, la realización de una sepultura, así como su altar o retablo en algún convento o iglesia, la admisión a religiosa para las hijas en determinadas instituciones, o el ocupar un lugar destacado en una iglesia durante la misa. Todo ello era sinónimo de perpetuación de la memoria de los donantes no solo entre sus coetáneos, sino también con menciones en los archivos o anales históricos aumentando por ende su status social.

9 GUIJO PÉREZ, Salvador: "Sobre la contratación...", op. cit.

${ }^{10}$ Para una mejor contextualización confróntese PALOMERO PÁRAMO, Jesús Miguel: El retablo sevillano del Renacimiento: análisis y evolución (1560-1629). Sevilla, 1983.

${ }^{11}$ LLORDÉN, Andrés: Convento de San Leandro de Sevilla (Notas y documentos para su historia). Málaga, 1973, p. 56. Confróntese, igualmente, PÉREZ ESCOLANO, Víctor: Juan de Oviedo y de la Bandera (1565-1625). Escultor, arquitecto e ingeniero. Sevilla, 1977, p. 239.

${ }^{12}$ LLORDÉN, Andrés: Convento de San Leandro..., op. cit., p. 57.

${ }^{13}$ LÓPEZ MARTÍNEZ, Celestino: Desde Martínez Montañés hasta Pedro Roldán. Sevilla, 1932, p. 199. 
una nota marginal. En ella se recogía que las religiosas "insistieron en que los relieves del antiguo [retablo] debían colocarse en el nuevo que se hacía"14, aludiendo a la enorme pena que sentían de que las piezas se perdieran. Estas creían que el valor del nuevo retablo, por mucho que tuviera, nunca sería comparable al anterior. No obstante, a causa de una mal entendida condescendencia, las religiosas tuvieron que acceder al reemplazamiento de las obras. Este nuevo retablo fue ejecutado por Pedro Duque Cornejo y su taller ${ }^{15}$. La documentación existente nos permite averiguar que Pedro Duque Cornejo ${ }^{16}$ se obligó a la realización de una serie de esculturas para el retablo mayor de San Leandro el 5 de septiembre de $1747^{17}$. El primitivo retablo se había vendido al padre José de Castro, provincial del Carmen Calzado. La cifra de la venta fue de 4.000 reales de vellón, tal y como se recoge en la declaración realizada por Teresa de Anguiano ${ }^{18}$, estando ubicado actualmente en la ciudad de Málaga. No corrieron afortunadamente el mismo destino las tallas que pertenecieron a este, las cuales se encuentran actualmente en el refectorio -tanto el San Leandro de bulto redondo, como los Santos Pedro y Pablo-, así como en el retablo mayor actual de la iglesia del monasterio -los seis

${ }^{14}$ AMSL (Archivo del monasterio de San Leandro), 24-1-1786, Misiva de una sola hoja rubricada por doña Francisca Rita de Espinosa Núñez de Prado y doña Lorenza Ignacia de Espinosa y Prado, hermanas. Fueron ambas abadesas del monasterio, tal y como se recoge en el Libro de elecciones (1748). La primera monja gobernó el monasterio desde el año 1765 hasta 1781, cuando comenzó la segunda hasta 1795.

${ }^{15}$ HALCÓN ÁLVAREZ-OSSORIO, Fátima; HERRERA GARCÍA, Francisco Javier y RECIO MIR, Álvaro: El retablo sevillano. Desde sus orígenes a la actualidad. Sevi1la, 2009, p. 314.

${ }^{16}$ Confróntese HERNÁNDEZ DÍAZ, José: Pedro Duque Cornejo y Roldán (16781757). Sevilla, 1983; PLEGUEZUELO HERNÁNDEZ, Alfonso: "Nuevos datos sobre la vida y la obra de Pedro Duque Cornejo", Archivo Hispalense, 205, 1984, pp. 179-188; y TAYLOR, René: El entallador e imaginero sevillano Pedro Duque Cornejo (1678-1757). Madrid, 1982.

${ }^{17}$ AHPS (Archivo Histórico Provincial de Sevilla), sección Protocolos Notariales, leg. 1358, f. 277. Citado por HERRERA GARCÍA, Francisco Javier: "Un nuevo grabado y últimas obras documentadas en Sevilla de Pedro Duque Cornejo", Laboratorio de Arte, 12, 1999, p. 246.

18 AMSL, 20-1-1748, Escritura de renuncia de los bienes de doña Teresa de Anguiano y Cárdenas como requisito de su profesión religiosa ante el escribano público don Dionisio Bravo. Recoge una declaración realizada por la misma donde diferencia las partidas de dinero sufragadas para la ejecución del nuevo retablo mayor y aquellas pertenecientes al dorado del de Nuestra Señora de Gracia. Del mismo modo, indicaba cómo estas partidas debían reemplazarse de las rentas y réditos que producían sus fincas. En esta misma se hacía alusión a la venta del retablo y la apreciación del mismo, así como el citado carmelita se comprometía para la adquisición de la obra en decir 1.000 misas rezadas, en cargo a los 4.000 reales de vellón en que se tasaba el retablo que adquirió. Este contrato de compraventa se realizó ante el mismo escribano el 26 de septiembre de 1747. 
citados relieves $^{19}$-. Desconocemos el paradero del resto del programa iconográfico proyectado y si este se realizó tal y como se describió.

Para comprender mejor lo expuesto y en parte como justificación del pesar de las religiosas, queremos resumir el contenido de unos papeles sueltos del convento, firmado por sus coetáneas, que aclaran el proceso de la sustitución. Ellos son prueba explícita y taxativa de los trámites seguidos y de la escasa o nula intervención de las religiosas en el reemplazamiento del mismo. La sustitución del retablo se debió única y exclusivamente al deseo de Teresa de Anguiano y Cárdenas, viuda desde muy joven de Melchor Calvo. Era natural de Sevilla, hija de Melchor Francisco de Anguiano y de María Leocadia de Cárdenas que, al sentirse en la flor de la edad envuelta por la prematura viudez, ingresó de novicia en San Leandro. Según el libro de profesiones del monasterio profesó a la edad de 27 años, el día 12 de noviembre de 1745, siendo visitador don Domingo Pérez de Ribera ${ }^{20}$.

Sucedió a su padre como única heredera de un enorme patrimonio como consta en la escritura del 2 de mayo de $1744^{21}$. Después de que profesó y una vez arregladas las cuentas con su padre, pudo disponer de 11.000 pesos escudos de a 128 cuartos, que fueron entregados al convento el 20 de junio de 1747 y se depositaron en las arcas de la clavería. Tras la imposición del depósito y recogidos los vales, el monasterio quedó libre de la responsabilidad del mismo, como consta

${ }^{19}$ Estos relieves son concretamente seis, actualmente dispuestos en las calles laterales del nuevo retablo. Representan el Bautismo de Cristo, la Flagelación, la Adoración de los Reyes, San Agustín, la Asunción de la Virgen y la Oración en el huerto de los olivos. Ninguno de ellos aparece en la documentación original relativa a la contratación del retablo por sus artífices y la comunidad, lo que nos hace suponer que la misma cambió durante el proceso de realización del mismo.

${ }^{20}$ AMSL, Libro de profesiones, 1700, Actas 130, 131, 138 y 139, ms.

${ }^{21}$ LLORDÉN, Andrés: Convento de San Leandro..., op. cit., p. 86. Esta escritura se extrae por parte de Llordén del AHPS, sección Protocolos Notariales, de la escribanía de Tomás de Gareaga. El mismo le otorgó la cantidad de 16.000 pesos de herencia; sin embargo, en vida de su progenitor recibió previamente de este otras cantidades: 2.000 pesos para su dote y gastos de profesión, 1.000 pesos por una letra dada a favor de don Thomás Macore y otros 2.000 pesos más de un vale realizado por don Manuel Hernández, sobrino y su cuñado, que se obligó a pagárselos a la vuelta de los navíos que estaban en La Habana. También le pertenecía la respetable cantidad de 6.000 pesos que había otorgado don José Landa a favor de su marido. Su padre sufragó los gastos y la mitad del costo de las celdas que se habían labrado en el monasterio para ella y su hermana doña Marcelina de Anguiano, que había profesado el 19 de marzo de 1744. Declaró la interesada, que a su muerte, recibiría el convento 2.000 ducados para que sus rentas se convirtiesen en gastos del culto en la octava de la Concepción. Extraído igualmente del AHPS, sección Protocolos Notariales, de la escribanía de Dionisio Bravo de Velasco el 10 de septiembre de 1745. LLORDÉN, Andrés: Convento de San Leandro..., op. cit., p. 87. 
en la escritura del 25 de enero de $1748^{22}$. Con el anterior caudal, Teresa, al ingresar en el convento, quiso en cierto modo perpetuar su nombre. Haciendo alarde de sus haberes, para inclinar el ánimo de las religiosas, ya antes de su profesión, a su costa mandó hacer y dorar el retablo de Nuestra Señora de Gracia ${ }^{23}$, deslumbrando así los ojos de la comunidad. Por ello, las mismas permitieron la sustitución del primitivo retablo del altar mayor por el actual, más en consonancia con las corrientes artísticas de aquel momento. Como ya indicamos, parece que el deseo de la comunidad no coincidió del todo con el de la donante ${ }^{24}$.

22 AMSL, sin fecha ni firma. Las citas anteriores se extraen igualmente de un documento recopilatorio realizado por las religiosas. Se encabezó con el título "Para sosiego de la abadesa y caso que sea necesario de caballero abogado". El mismo se realizó presumiendo las posibles reclamaciones a la abadesa y al convento ante el impago y la no finalización del retablo mayor por parte de doña Teresa de Anguiano, que se presume falleció dejando el mismo sin terminar. Este recopilatorio vuelve a hacer referencia al acta de renuncia de doña Teresa de Anguiano, dándole validez esta vez desde el día 27 de enero de 1748. En él se recogía que con motivo de haber hecho un retablo nuevo en el altar mayor, "diferente del que había labrado y dorado antes de su profesión a Nuestra Señora de Gracia y que diferentes partidas de dinero, que había gastado en el retablo del altar mayor, se habían de reemplazar de las rentas y réditos que producían sus fincas, en que estaban situados sus caudales".

23 AMSL, sin fecha ni firma. Desconocemos a qué retablo de Nuestra Señora de Gracia pudiera referirse, pues la única imagen que se conoce en la iglesia con dicha advocación corresponde al alto relieve puesto en el ático del retablo de San Agustín. Se trata de un recuadro con la imagen de Nuestra Señora de Gracia, y sobre ella corona el retablo las Virtudes Teologales. Si no fuera esa pudiera referirse a otro que estuviera dentro de la clausura, cuya existencia ignoramos.

${ }^{24}$ AMSL, 24-1-1786: "La religiosa Doña Teresa de Anguiano dijo quería hacer el retablo del altar mayor, y aunque las religiosas sentían se quitase el que tenían por ser de artífices de estimación, se condescendió por agradecer la voluntad que nos tenía. Pero insistieron en que los relieves se habían de colocar en el nuevo que se hacía, y si hubieran entendido que no llegaría a dorarlo, en ninguna manera lo hubieran permitido y quizá por toda la comunidad. Era su voluntad dorarlo, porque, cuando le trajeron el dinero de las Indias, celebró entre las religiosas tenía para hacerlo, lo que no ejecutó. Quién hiciese el retablo, pagar su costo y cuentas que en esto hubo, fue dueño con voluntad de nuestra religiosa el señor administrador Don Manuel Antonio del Saz, como que manejaba sus caudales y la comunidad no hubo intervención, ni aun en saber en cuánto se vendía su retablo, monumento, sitial de tela y, he oído a las religiosas que dos candeleros de plata, y se nos dijo que la que está puesta en la puerta del sagrario era de las que se había quitado de nuestra corona de plata. Esto se hizo en la confianza de que dicha religiosa tenía caudales para costearlo hasta dorarlo y dicho administrador Don Manuel Antonio del Saz, que lo disponía, se estuvo en la posición de que era una memoria de su voluntad y en cuantos años vivió después no habló en que el convento le debiese del retablo, sí sentiría no dorarlo, como que fiadas en que lo había de dar completo, se permitió quitase el que nosotras teníamos, 
El retablo realizado por Duque Cornejo (Figura 1) constaba de dos cuerpos y ático. Desconocemos los artistas y artesanos que participaron en el ensamblaje del retablo y en su finalización. Según consta en la escritura, Pedro Duque Cornejo se comprometió con el administrador de la religiosa, don Manuel Antonio del Saz, en nombre de su comunidad. Este era presbítero del hospital del Cardenal. En dicho compromiso se recogió la realización de dos esculturas de tamaño natural de Santa Teresa y Santa Bárbara junto con una escena de una visión de San Agustín en tamaño mayor al natural. También seis ángeles para mantener "los bancos de dicho retablo y dos querubines de media bara" 25 . La escritura no hizo referencia a la imagen principal del titular del monasterio, San Leandro, ni tampoco de la pintura que ocuparía la hornacina central del segundo cuerpo. Sí sabemos mediante una segunda escritura que el mismo autor canceló su compromiso antes de lo previsto mediante carta de pago del día 23 de enero de $1748^{26}$. El retablo no se concluiría hasta posiblemente 1752, fecha en la que la iglesia fue estrenada de nuevo tras una importante remodelación ${ }^{27}$.

El retablo quedó dividido en tres calles flanqueadas por estípites. En las laterales del primer cuerpo se colocaron las esculturas de las Santas Bárbara y Teresa (Figuras 2-3), en honor a la donante, mientras que la imagen de San Leandro ocupaba la hornacina central. El segundo cuerpo estaba presidido por un lienzo dedicado a la Pura Concepción, obra del pintor Domingo Martínez, el cual era rematado en su ático por la Visión de San Agustín positus in medio, entre la Virgen y su Hijo, coronados por las figuras del Padre Eterno y el Espíritu Santo (Figura 4), tal y como se recogía en el contrato. Acotando toda esta iconografía en sus calles laterales se encontraban las seis tablas pertenecientes al primitivo retablo de 1582. En el banco del retablo se disponían los seis ángeles atlantes junto al resto de la corte celeste elegantemente colocada sobre todo el retablo. Estas obras no se atribuyen en su totalidad directamente al autor sino que son obras de su taller, destacando entre sus discípulos, probablemente, Felipe Fernández del Castillo ${ }^{28}$.

Fecha de recepción: 30 de octubre de 2018

Fecha de aceptación: 1 de julio de 2019

y para que en todo tiempo conste hago esta declaración en este mi convento del señor San Leandro en 24 de enero de 1786".

${ }^{25}$ HERRERA GARCÍA, Francisco Javier: "Un nuevo grabado...”, op. cit., p. 246.

${ }^{26}$ AHPS, sección Protocolos Notariales, leg. 1359, f. 26. Citado en HERRERA GARCÍA, Francisco Javier: "Un nuevo grabado...", op. cit., p. 246.

${ }^{27}$ MATUTE Y GAVIRA, Justino: Anales eclesiásticos y seculares de la muy noble y muy leal ciudad de Sevilla. T. II. Sevilla, 1887, pp. 105-106. Las obras de la iglesia finalizaron previamente al 14 de junio de 1752, día de su estreno.

${ }^{28}$ HERRERA GARCÍA, Francisco Javier: "Un nuevo grabado...”, op. cit., p. 246. 


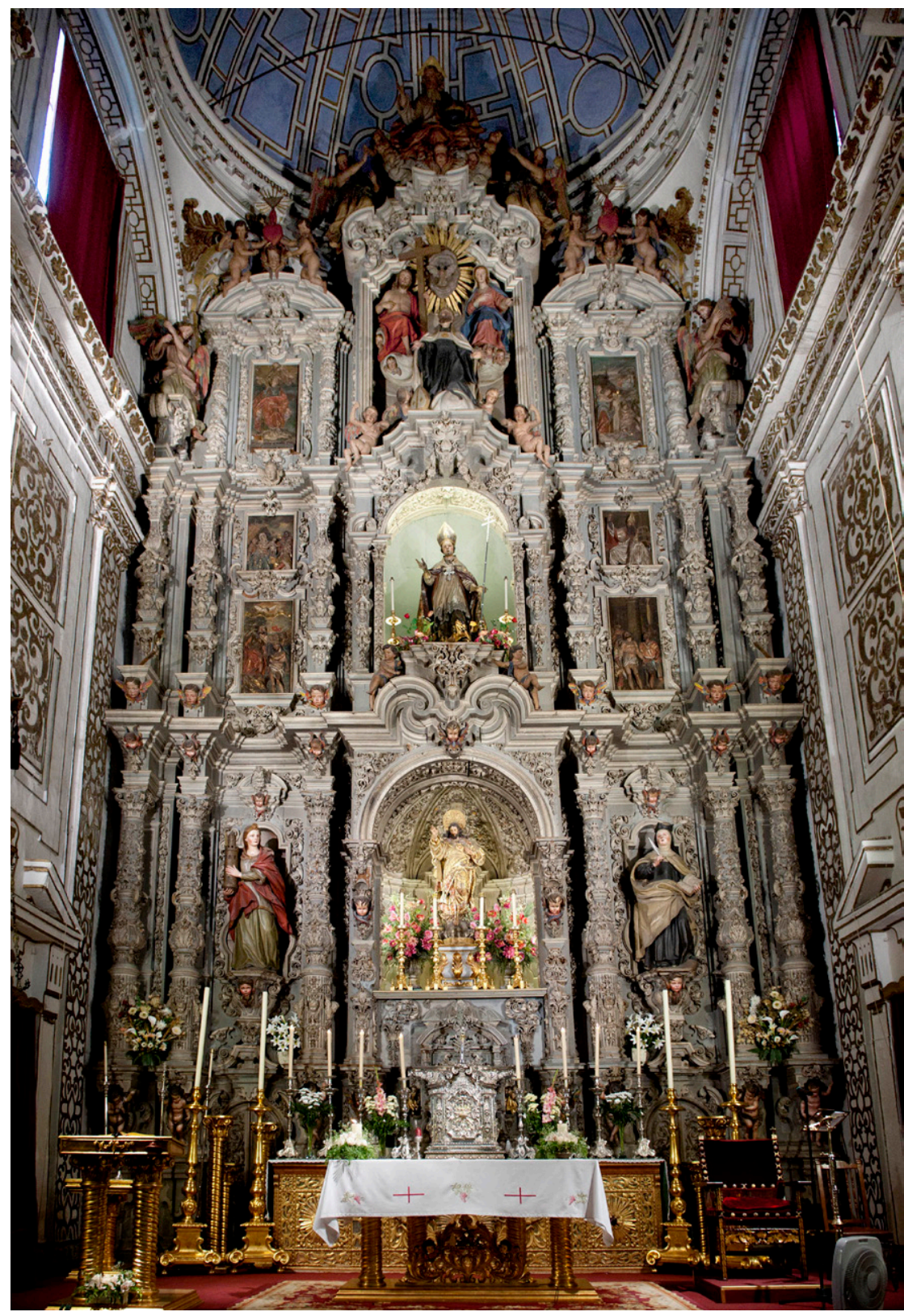

Figura 1. Pedro Duque Cornejo, Retablo mayor, 1747, monasterio de San Leandro, Sevilla. Foto: Antonio del Junco.

LABORATORIO DE ARTE 31 (2019), pp. 671-682, ISSN 1130-5762 e-ISSN 2253-8305 - DOI http://dx.doi.org/10.12795/LA.2019.i31.41 


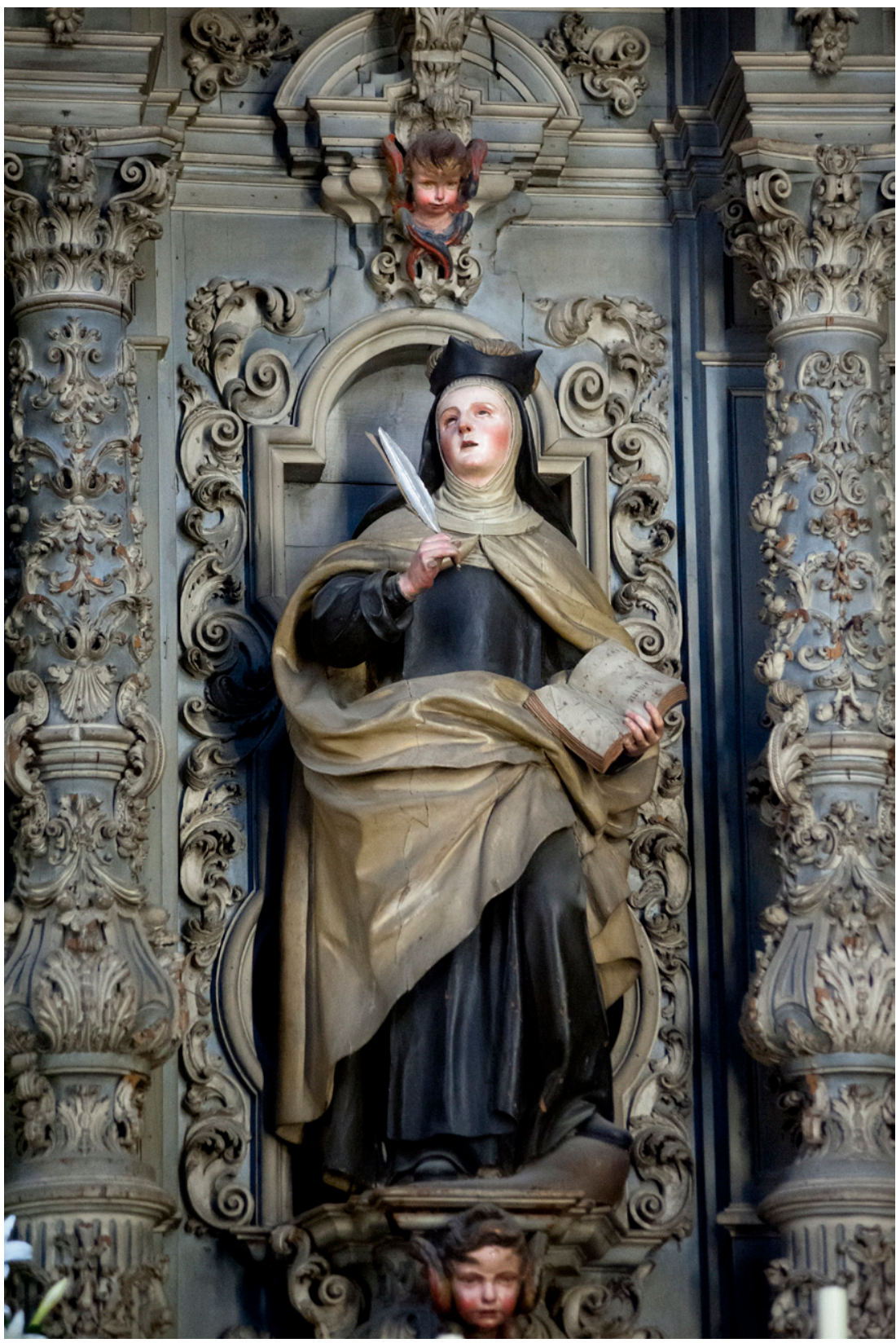

Figura 2. Pedro Duque Cornejo, Santa Teresa (retablo mayor), 1747, monasterio de San Leandro, Sevilla. Foto: Antonio del Junco. 


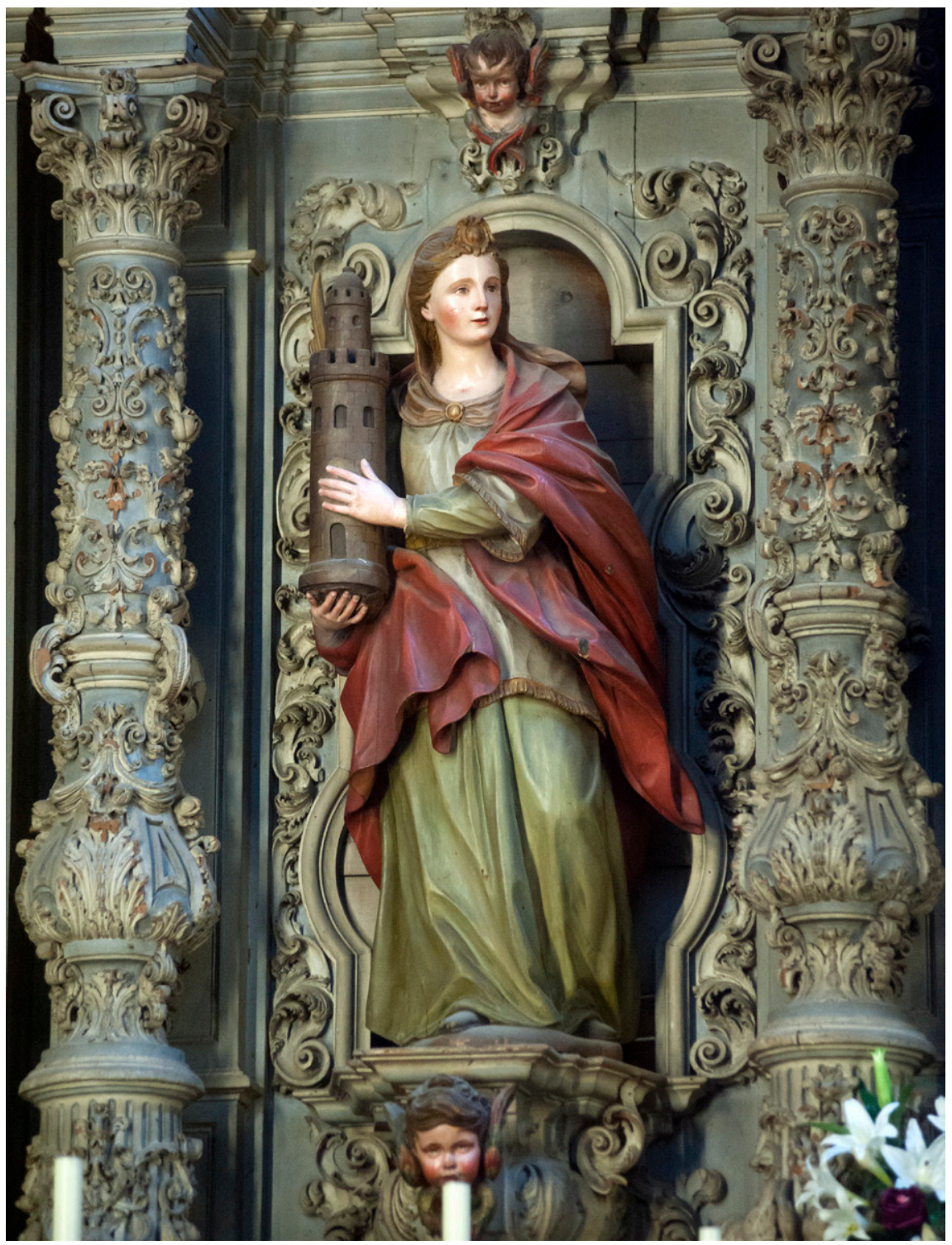

Figura 3. Pedro Duque Cornejo, Santa Bárbara (retablo mayor), 1747, monasterio de San Leandro, Sevilla. Foto: Antonio del Junco. 


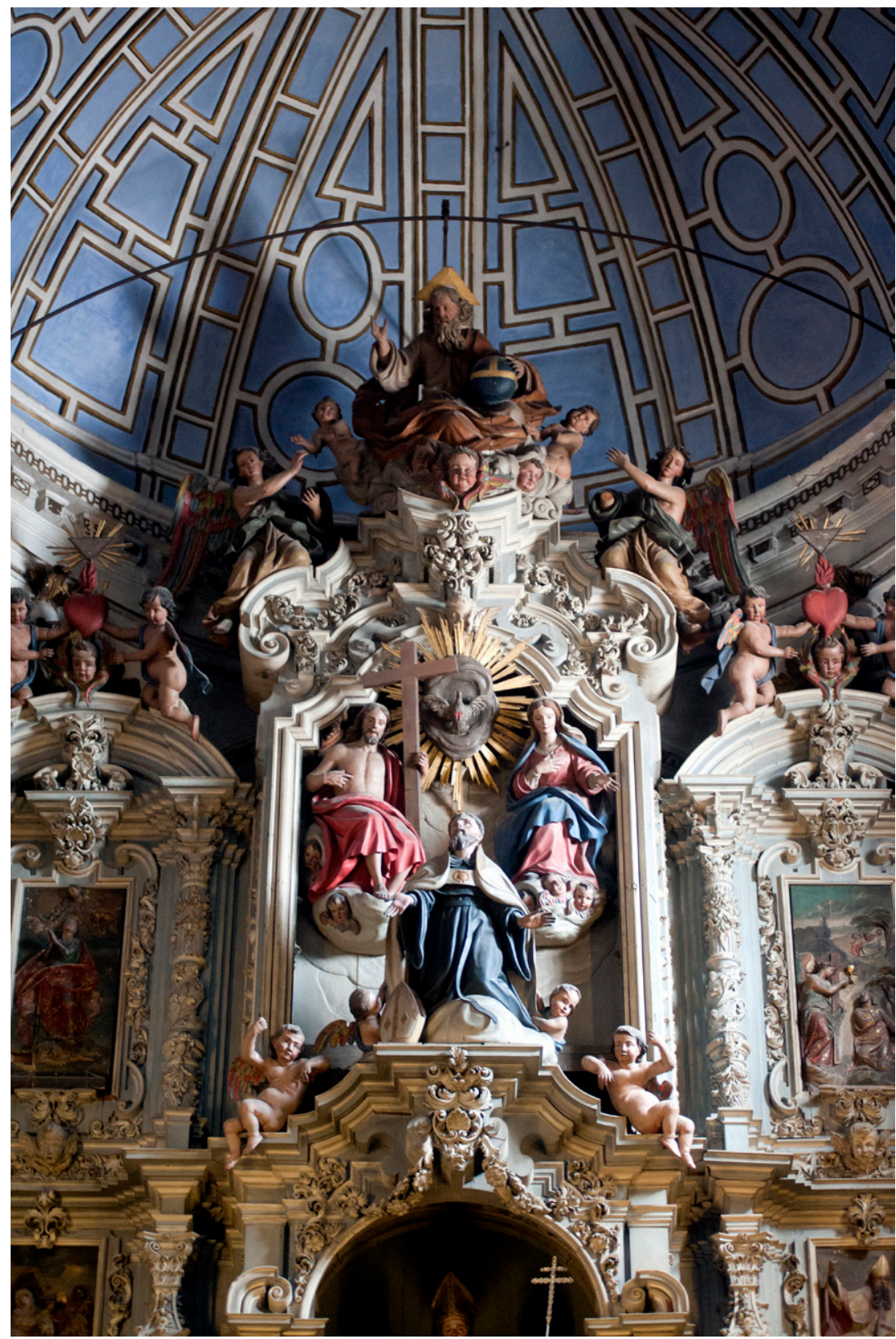

Figura 4. Pedro Duque Cornejo, San Agustín positus in medio (retablo mayor), 1747, monasterio de San Leandro, Sevilla. Foto: Antonio del Junco. 